\title{
The lithosphere-asthenosphere boundary observed with USArray receiver functions
}

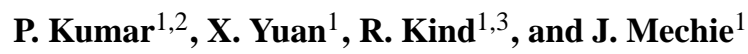 \\ ${ }^{1}$ Deutsches GeoForschungsZentrum GFZ, Potsdam, Germany \\ ${ }^{2}$ National Geophysical Research Institute NGRI (CSIR), Hyderabad, India \\ ${ }^{3}$ Freie Universität Berlin, Fachbereich Geowissenschaften, Berlin, Germany \\ Correspondence to: R. Kind (kind@gfz-potsdam.de) \\ Received: 30 November 2011 - Published in Solid Earth Discuss.: 6 January 2012 \\ Revised: 17 April 2012 - Accepted: 30 April 2012 - Published: 24 May 2012
}

\begin{abstract}
The dense deployment of seismic stations so far in the western half of the United States within the USArray project provides the opportunity to study in greater detail the structure of the lithosphere-asthenosphere system. We use the $\mathrm{S}$ receiver function technique for this purpose, which has higher resolution than surface wave tomography, is sensitive to seismic discontinuities, and is free from multiples, unlike $\mathrm{P}$ receiver functions. Only two major discontinuities are observed in the entire area down to about $300 \mathrm{~km}$ depth. These are the crust-mantle boundary (Moho) and a negative boundary, which we correlate with the lithosphere-asthenosphere boundary (LAB), since a low velocity zone is the classical definition of the seismic observation of the asthenosphere by Gutenberg (1926). Our S receiver function LAB is at a depth of 70-80 km in large parts of westernmost North America. East of the Rocky Mountains, its depth is generally between 90 and $110 \mathrm{~km}$. Regions with LAB depths down to about $140 \mathrm{~km}$ occur in a stretch from northern Texas, over the Colorado Plateau to the Columbia basalts. These observations agree well with tomography results in the westernmost USA and on the east coast. However, in the central cratonic part of the USA, the tomography LAB is near $200 \mathrm{~km}$ depth. At this depth no discontinuity is seen in the $S$ receiver functions. The negative signal near $100 \mathrm{~km}$ depth in the central part of the USA is interpreted by Yuan and Romanowicz (2010) and Lekic and Romanowicz (2011) as a recently discovered midlithospheric discontinuity (MLD). A solution for the discrepancy between receiver function imaging and surface wave tomography is not yet obvious and requires more high resolution studies at other cratons before a general solution may be found. Our results agree well with petrophysical models of
\end{abstract}

increased water content in the asthenosphere, which predict a sharp and shallow LAB also in continents (Mierdel et al., 2007).

\section{Introduction}

The radial structure of the Earth's interior is basically determined from seismology. The main elements of Earth structure are separated by seismic discontinuities (Moho, 410 and 660 discontinuities, core-mantle boundary, inner core boundary). At about the same time as when the first seismic models were obtained, Wegener (1912) suggested that continents drift laterally over thousands of kilometers, and the existence of an elastic lithosphere overlying a plastic asthenosphere was postulated (Barrell 1914). Gutenberg (1926) suggested that a seismic low velocity zone in the upper mantle, which he had deduced from $\mathrm{P}$ phase observations, could possess reduced viscosity and thus permit continents to move laterally. Until now, the lithosphere-asthenosphere boundary (LAB) is still the poorest known boundary, although it is probably the most important boundary for the description of the drifting plates. Modern global reference models have averaged crustal models, but almost no indication of the lithosphereasthenosphere system.

Models for the causes of the asthenosphere could be the enrichment of volatiles due to increased temperature (e.g. Priestley and McKenzie, 2006) or increased water content leading to silicate melt (e.g. Mierdel et al., 2007). Karato (2012) suggested grain sliding, which explains two sharp seismic low velocity zones near about 100 and $200 \mathrm{~km}$ depth 


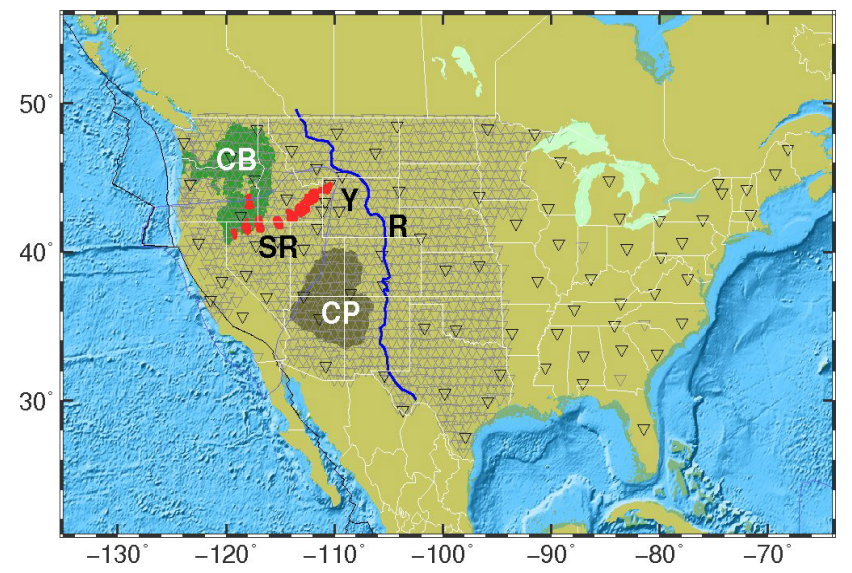

Fig. 1. Map of the seismic stations used for this study. Dense light inverted triangles: USArray stations at the beginning of 2011; sparse dark inverted triangles: permanent stations. Key: $\mathrm{CP}=$ Colorado Plateau, $\mathrm{CB}=$ Columbia basalts, $\mathrm{R}=$ Rocky Mountains front, $\mathrm{Y}=$ Yellowstone Caldera, $\mathrm{SR}=$ Snake River calderas.

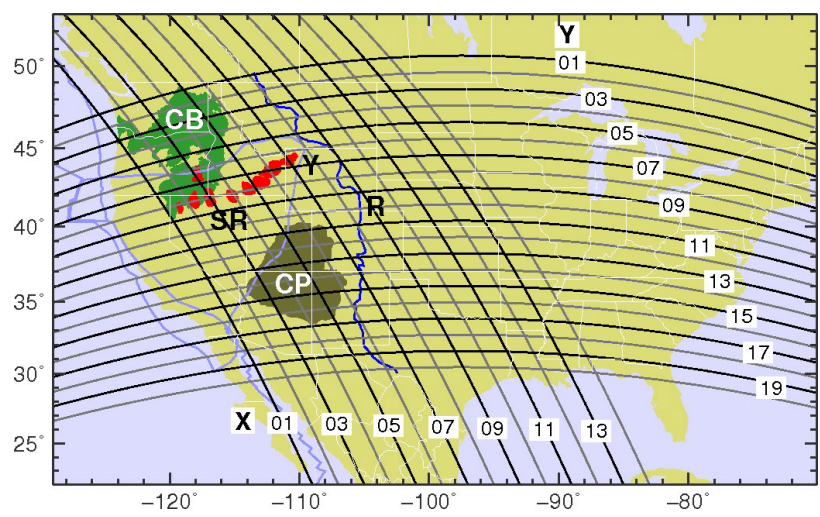

Fig. 2. Location of $S$ receiver function profiles across the station network. Key: see Fig. 1.

under continents. Temperature effects predict a broad LAB at depths near $200 \mathrm{~km}$ below continents, whereas water content predicts a sharper and shallower LAB beneath continents. Several geophysical observations of the LAB are compared by Eaton et al. (2009).

Since the times of Gutenberg, seismologists have been searching for low velocity zones in the upper mantle that could represent the asthenosphere. A low velocity zone is difficult to detect with wide-angle body waves, because their travel-time curves do not exhibit signals that travel with the wave speed inside the low velocity zone. Nevertheless, Thybo and Perchuc (1997) and Thybo (2006) reported about a shallow low velocity zone in the continental mantle globally ( $8^{\circ}$ discontinuity), observed in short period wide-angle data (mainly controlled source). However, seismic surface wave tomography became the essential method in studying the lithosphere-asthenosphere system, although
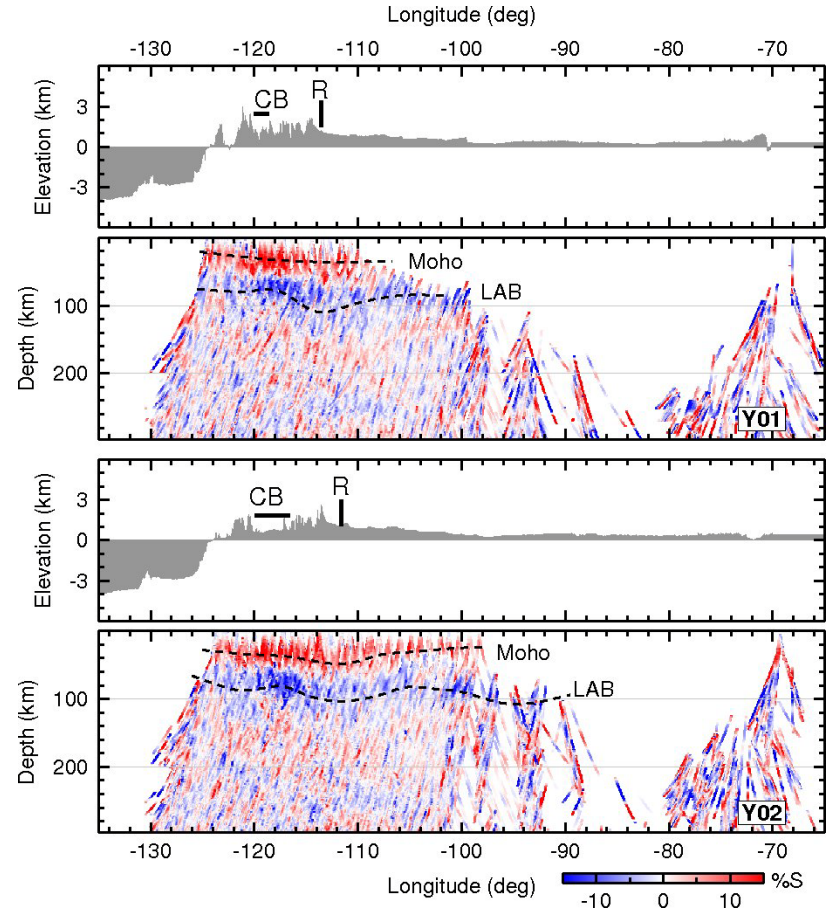

Fig. 3. Two migrated $S$ receiver function profiles: Y01 and Y02, across the station network. Names of the profiles are given in the lower right. Moho (red, positive conversion) and LAB (blue, negative conversion) are marked. Key: see Fig. 1. Dashed lines for Moho and LAB are drawn by hand and mark approximately the depth distribution of these discontinuities. The seismic data have been filtered with an $8 \mathrm{~s}$ low-pass filter.

it is relatively insensitive to discontinuities and has less resolution than body waves due to longer periods. For a recent review of the deep structure of cratons using surface waves and of a description of the method, see e.g. Lebedev et al. (2009). Body waves in the form of scattered waves are now used again to a larger extent to study the lithosphereasthenosphere system. The so-called "receiver functions" are short period scattered teleseismic signals converted from $P$ to $\mathrm{S}$ waves, or vice versa, at seismic discontinuities beneath a recording station. See Li et al. (2004) for an early application at the Hawaiian plume and Yuan et al. (2006), Kumar et al. (2006) and Kind et al. (2012) for a description of the technique. Kumar and Kawakatsu (2011) have shown good examples of a subducting LAB in oceanic environments. Rychert and Shearer (2009) have compiled a global map of the $\mathrm{LAB}$ from $\mathrm{P}$ receiver function observations (see also Romanowicz, 2009). They found a negative discontinuity near $100 \mathrm{~km}$ depth in many continental regions, which they said may not be the LAB, because the LAB is thought to be deeper under continents. Fischer et al. (2010) have compiled global $\mathrm{S}$ receiver function studies showing signals considered as being caused by the LAB. The two receiver function techniques to observe the $\mathrm{LAB}$, the $\mathrm{P}$ and the $\mathrm{S}$ 

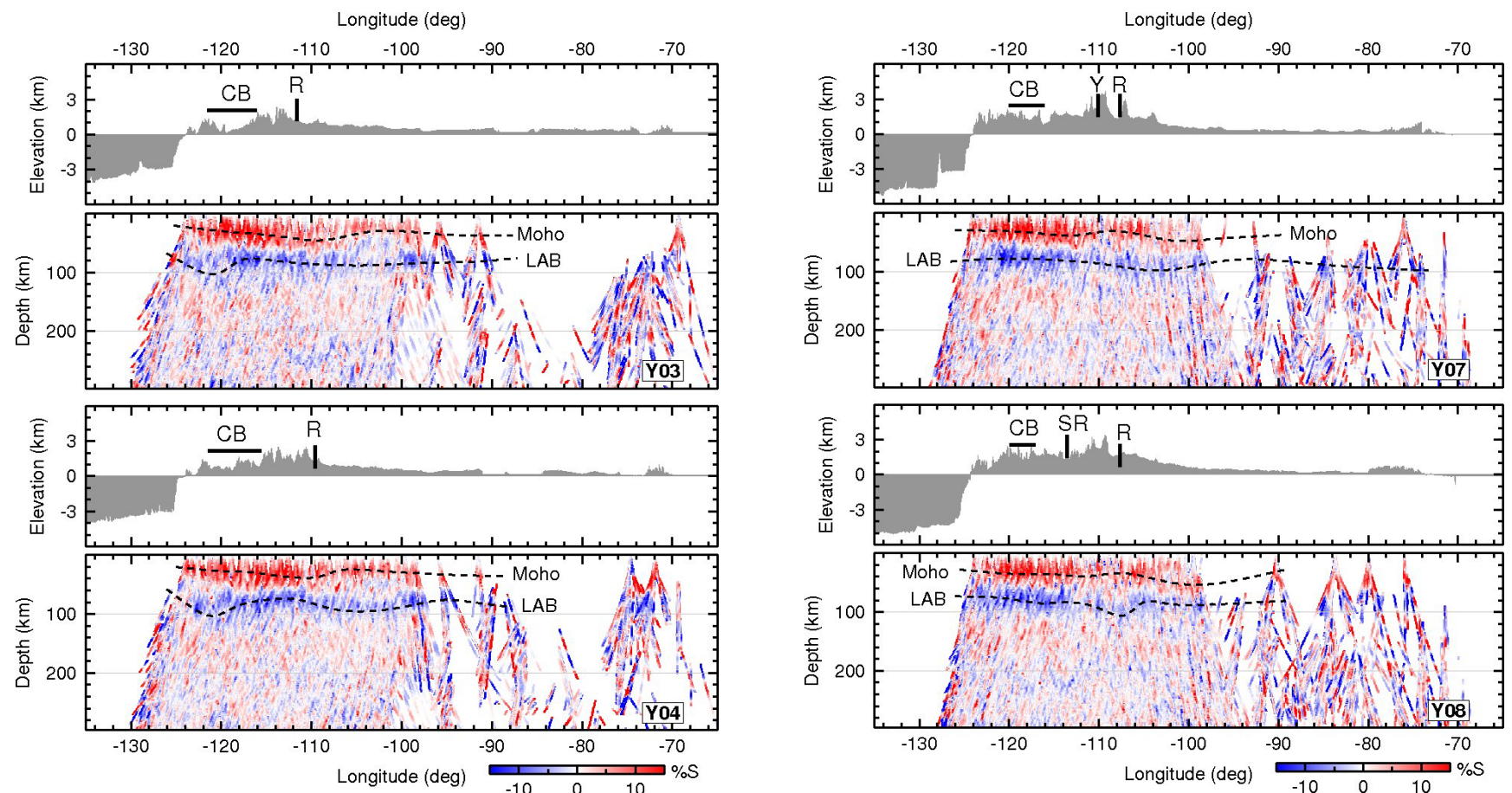

Fig. 4. Migrated S receiver functions along profiles $\mathrm{Y} 03$ and $\mathrm{Y} 04$ as in Fig. 3.

Fig. 6. Migrated S receiver functions along profiles $\mathrm{Y} 07$ and $\mathrm{Y} 08$ as in Fig. 3.
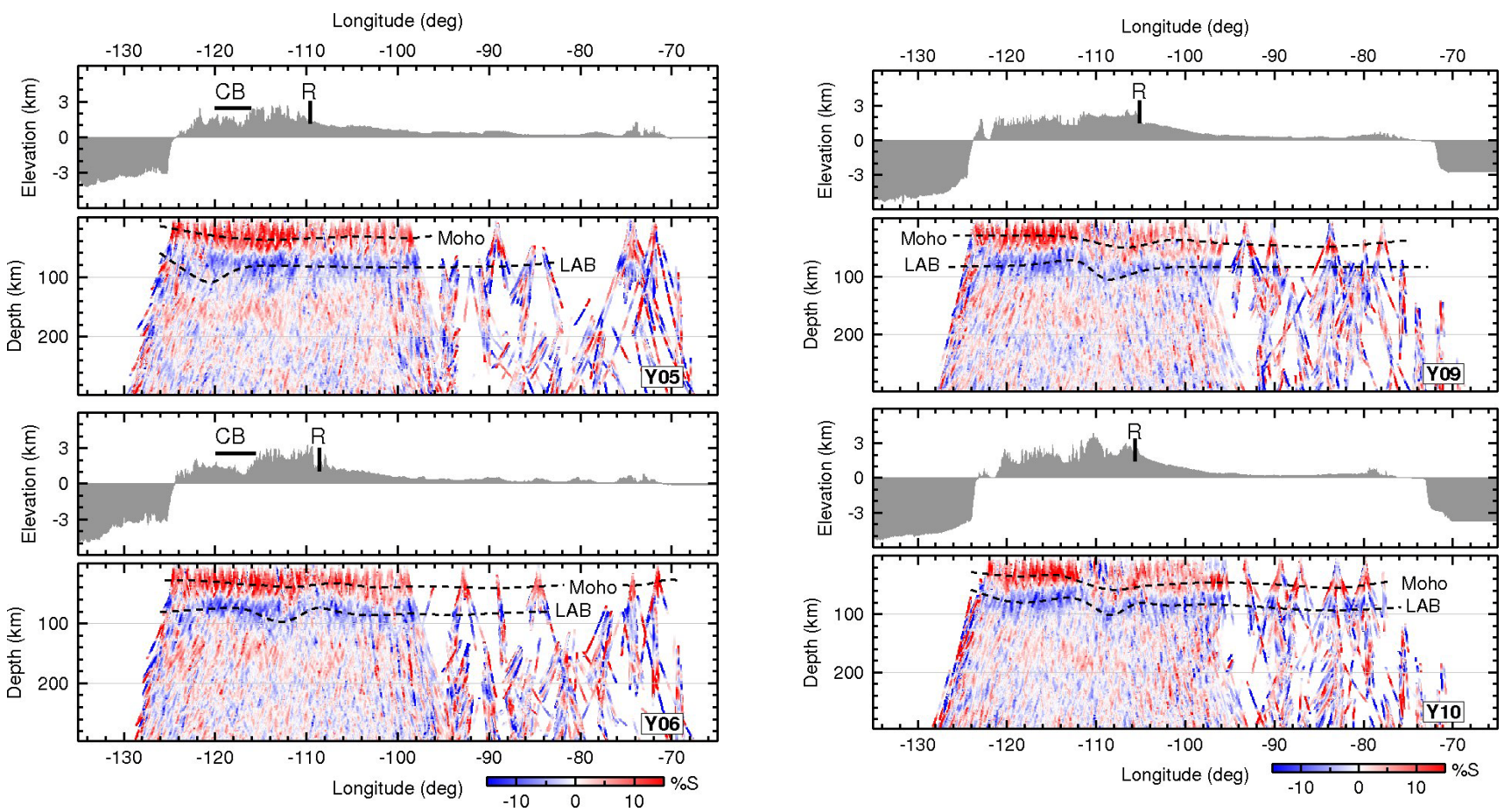

Fig. 5. Migrated S receiver functions along profiles $\mathrm{Y} 05$ and $\mathrm{Y} 06$ as in Fig. 3.

Fig. 7. Migrated S receiver functions along profiles $\mathrm{Y} 09$ and $\mathrm{Y} 10$ as in Fig. 3. 

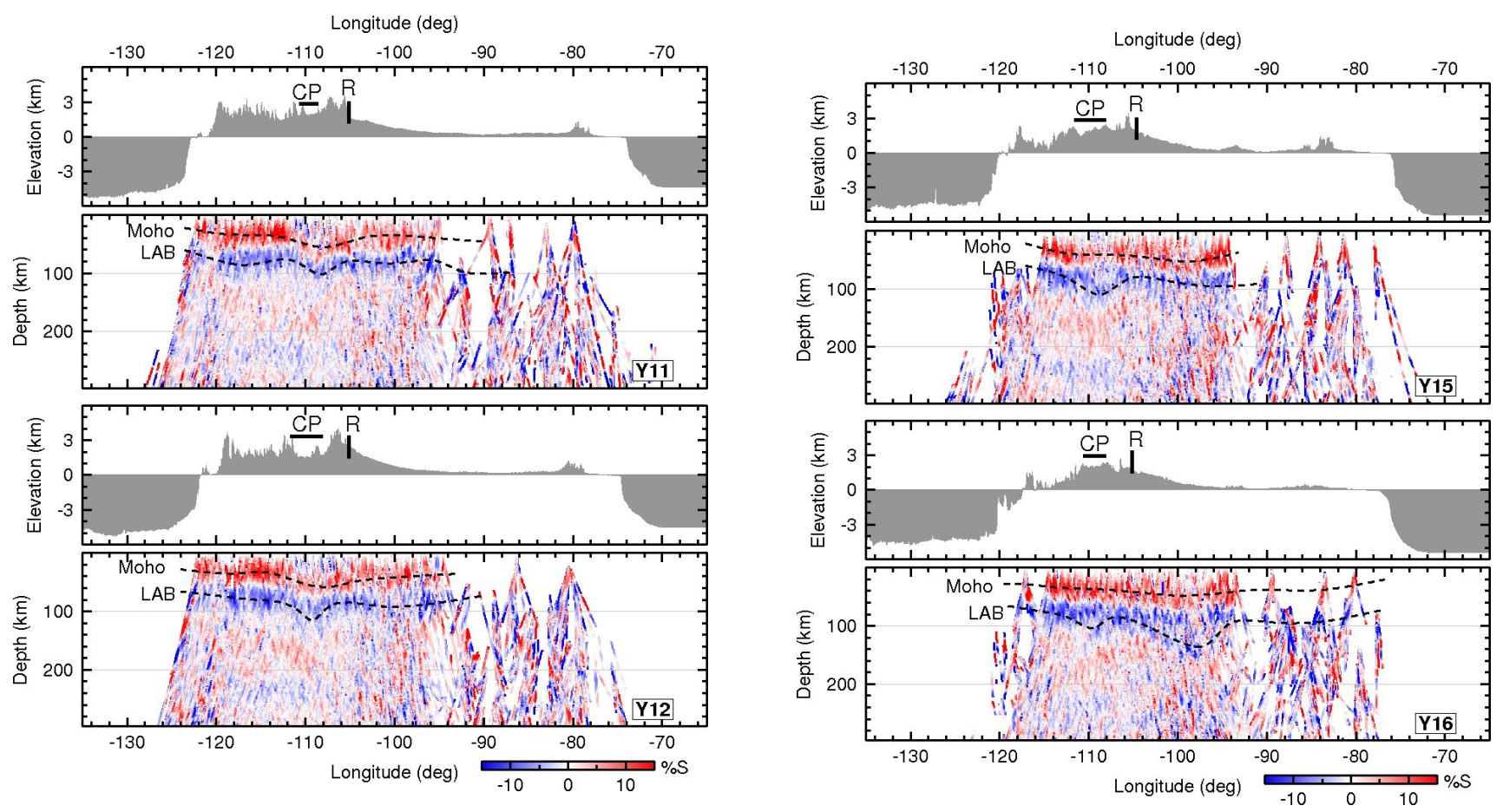

Fig. 8. Migrated S receiver functions along profiles Y11 and Y12 as in Fig. 3.
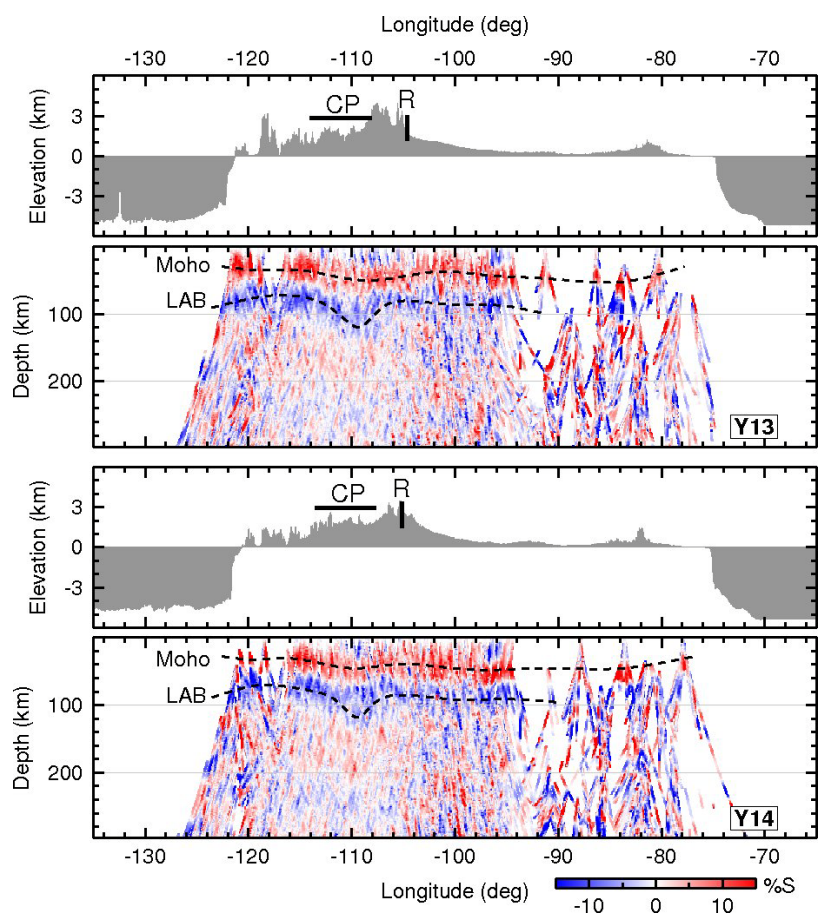

Fig. 10. Migrated S receiver functions along profiles $\mathrm{Y} 15$ and $\mathrm{Y} 16$ as in Fig. 3. It seems that along profile Y16 besides the marked LAB another, shallower blue signal exists. The north-south profiles X07X09 confirm deepening of the LAB at the same location. The shallower blue signal in profile Y16 might be caused by heterogeneities off the profile.

receiver functions, differ in an important detail. In $\mathrm{P}$ receiver functions the LAB signal may be overwhelmed by multiples from the Moho or internal crustal discontinuities. In contrast, in $\mathrm{S}$ receiver functions direct conversions and multiples are clearly separated. Therefore, $S$ receiver functions are less affected by possible misinterpretations.

Abt et al. (2010) and Ford et al. (2010) have compared $\mathrm{LAB}$ observations from $\mathrm{S}$ receiver functions and surface wave tomography studies in North America and Australia, respectively. Abt et al. (2010) found disagreement in the old cratonic part of the USA. Here, the surface wave LAB is near $200 \mathrm{~km}$ depth, and $\mathrm{S}$ receiver functions observe a negative discontinuity near $100 \mathrm{~km}$ depth. No clear $S$ receiver function signal was observed near the cratonic surface wave LAB $(\sim 200 \mathrm{~km})$ and no surface wave signal near the cratonic $S$ receiver function signal $(\sim 100 \mathrm{~km})$. In the westernmost USA both techniques agree in their observations of the LAB near depths of $100 \mathrm{~km}$ or less. The shallow negative $\mathrm{S}$ receiver function signal in the cratonic part of the USA was named mid-lithospheric discontinuity (MLD). This discontinuity may be identical with the $8^{\circ}$ discontinuity postulated for the continental mantle by Thybo and Perchuc (1997) and Thybo (2006). Miller and Eaton (2010) observed in S receiver functions two signals from low velocity zones in

Fig. 9. Migrated S receiver functions along profiles Y13 and Y14 as in Fig. 3. 


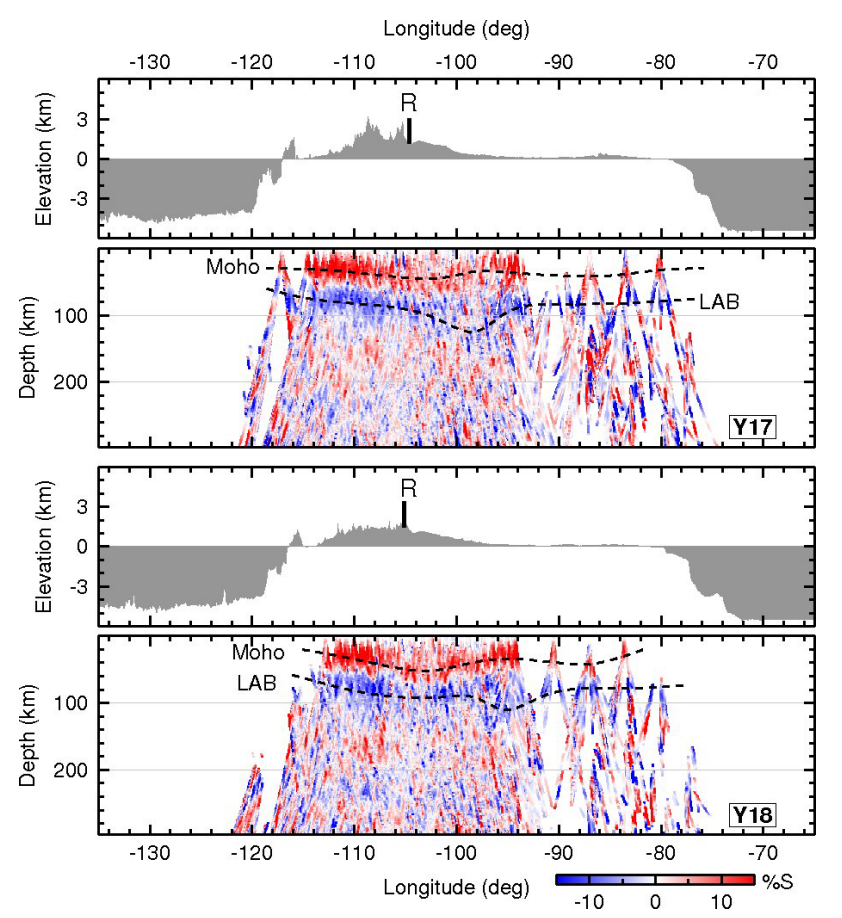

Fig. 11. Migrated S receiver functions along profiles Y17 and Y18 as in Fig. 3.
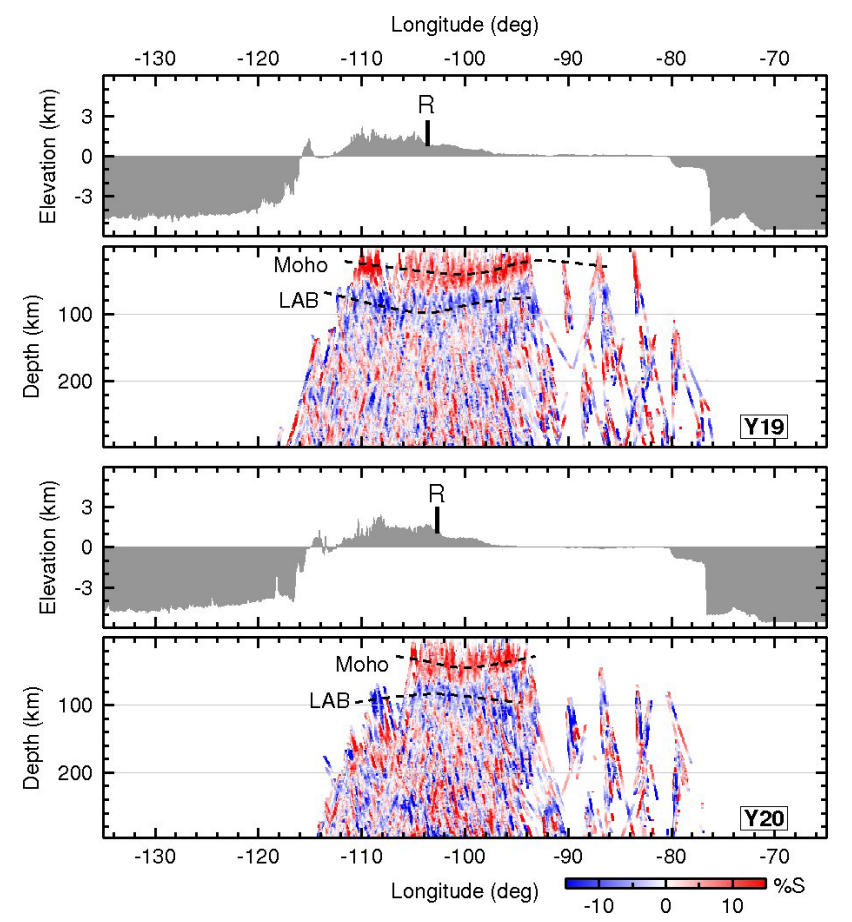

Fig. 12. Migrated S receiver functions along profiles $Y 19$ and Y20 as in Fig. 3.

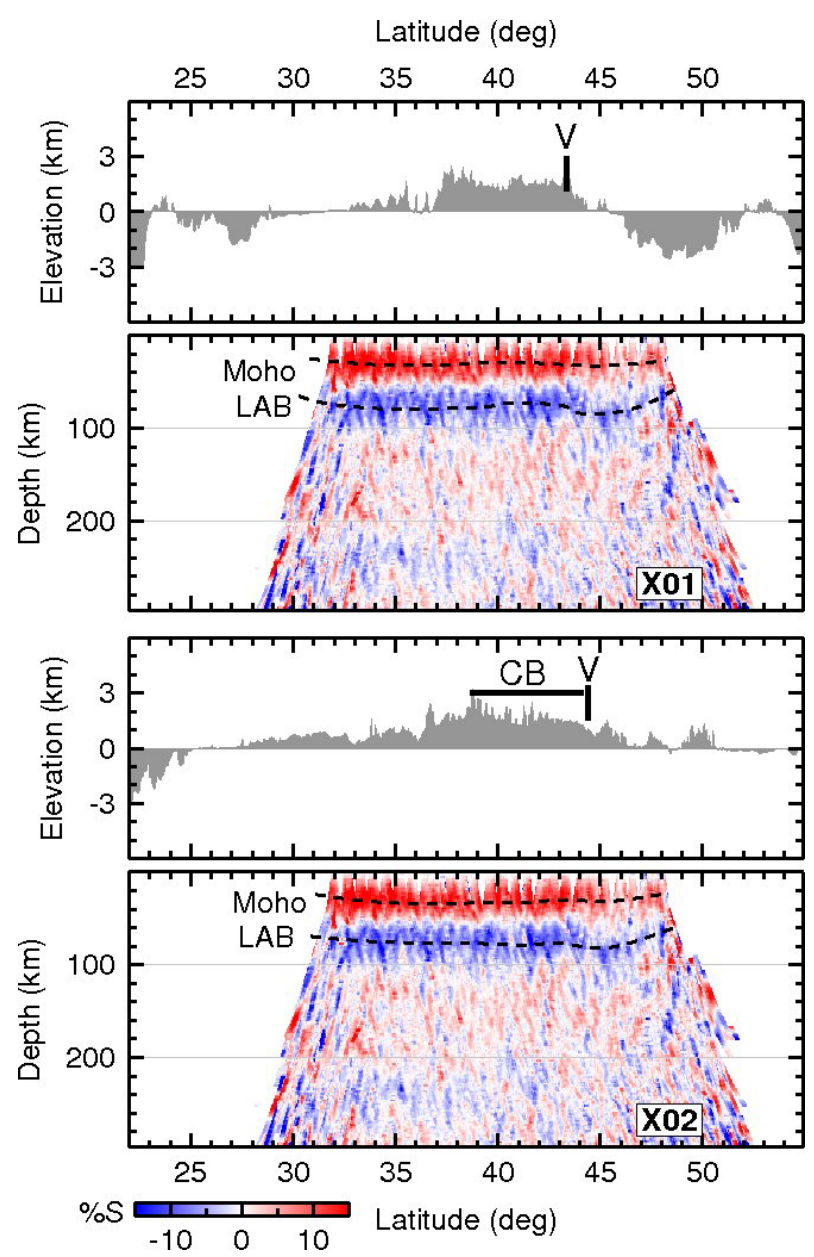

Fig. 13. Migrated $S$ receiver functions along profiles $\mathrm{X} 01$ and $\mathrm{X} 02$ as in Fig. 3.

the cratonic parts of Canada and interpreted the shallower one as a remnant slab. Lekic and Romanowicz (2011) also observed, with improved tomography techniques, the MLD near $100 \mathrm{~km}$ depth and the LAB at 200-250 km depth globally in cratonic regions. Two LABs, a deeper and a shallower one, have been observed in $\mathrm{S}$ receiver functions by Zhao et al. (2011) in Tibet as an indication of the Tibetan lithosphere overriding the Asian lithosphere. The overall lithospheric thickness in Tibet reaches about $250 \mathrm{~km}$, which is in very good agreement with surface wave results (e.g. Priestley and McKenzie, 2006). In South Africa two negative phases are also found: one at $150-200 \mathrm{~km}$ and the second one near $300 \mathrm{~km}$ (Kästle, 2011). It seems that also in the east European platform, two negative converters may exist above each other (Geissler et al., 2010). These observations indicate that the lithospheric structure of the various cratons may differ greatly. This leads to a number of questions concerning especially the cratonic lithosphere. Is the LAB deep or shallow? Are there two LABs in some places? What is the MLD? Why 

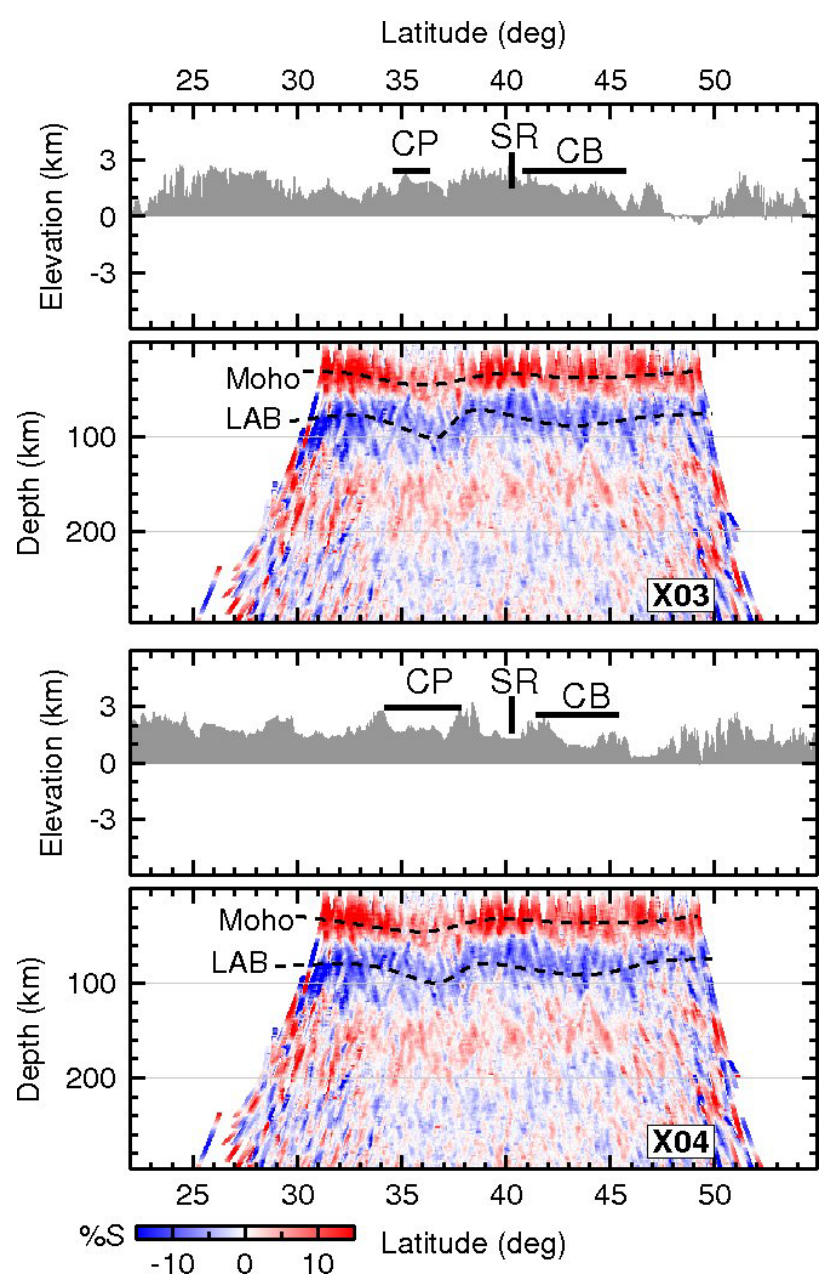

Fig. 14. Migrated S receiver functions along profiles X03 and X04 as in Fig. 3 .

is the surface wave LAB in the central parts of the USA not observed with $S$ receiver functions? The solution can only be found with more and better data. Significantly more data are already available in the western half of the USA. These are the openly available USArray data. Some earlier results have been published by Kumar et al. (2012). Here, we present the full amount of presently available $\mathrm{S}$ receiver function data from the upper mantle in the USA.

\section{Data and observations}

The website http://www.usarray.org/ provides detailed information about the USArray project. More than 400 seismic stations are installed in an area of the USA with about $70 \mathrm{~km}$ average spacing. After a period of two years, they are moved to a neighbouring area, thus covering successively the entire territory of the USA. The resulting huge amount of seismic data is openly available through IRIS (http://www.iris.edu/

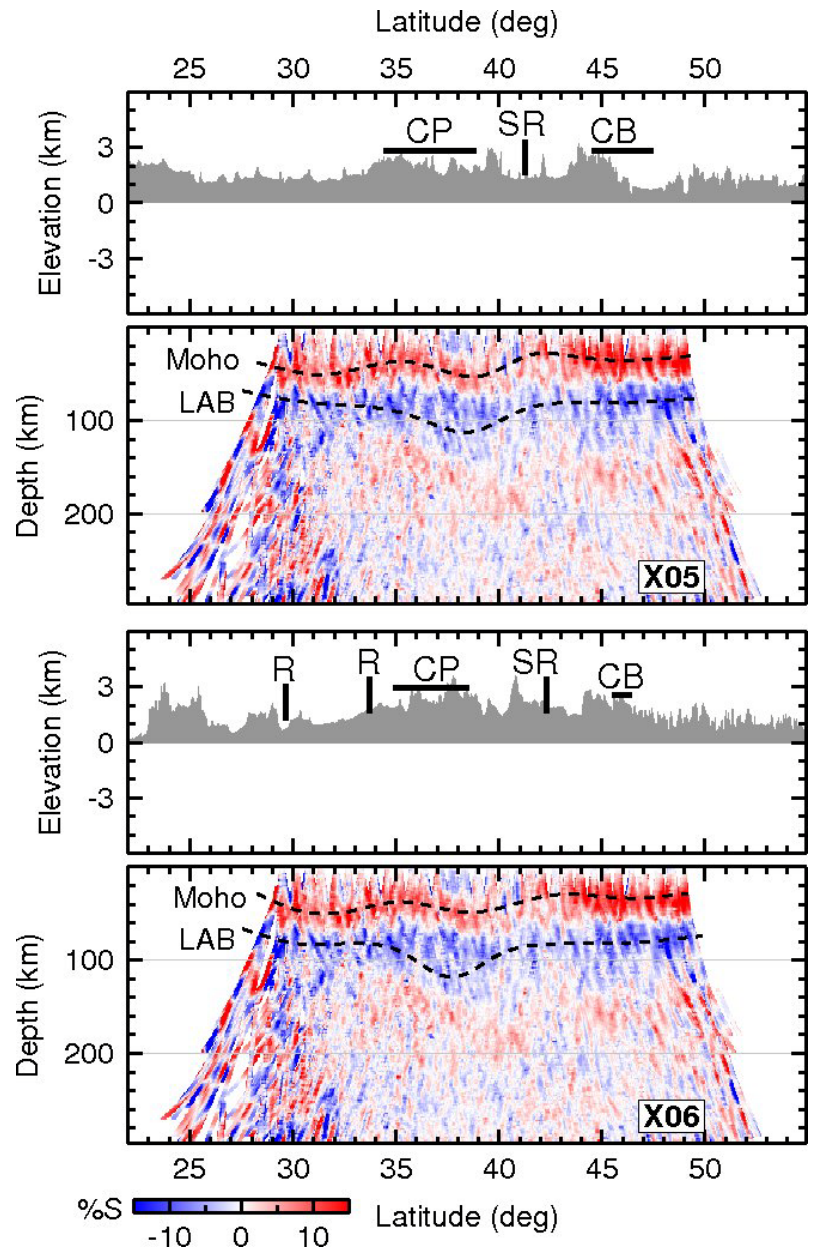

Fig. 15. Migrated S receiver functions along profiles X05 and X06 as in Fig. 3.

hq/). Up to now the western half of the USA is covered. The stations we used for our study are shown in Fig. 1. They include also permanent stations. We derived $\mathrm{S}$ receiver functions from all stations. Due to the large amount of waveform data, the processing was performed using an automatic approach. We used magnitude $(>=5.9 \mathrm{mb})$ as the criterion for selecting the waveforms. The three-component Z-N-E records of the $\mathrm{S}$ and SKS waveforms were rotated into a raybased L-Q-T coordinate system, oriented in the P-SV-SH directions, and then the $\mathrm{L}$ component was deconvolved by the $\mathrm{S}$ signal on the $\mathrm{Q}$ component. Theoretical back-azimuth angles were used in the rotation. The S-wave incidence angles were estimated by automatically minimizing the SV-wave energy on the $\mathrm{Q}$ component within a time window spanning \pm 1 s on either side of the theoretical S-onset (e.g. Kumar et al., 2006). The obtained $S$ receiver functions were time-reversed about the arrival time of the $S$ wave and reversed in amplitude sign. All final $\mathrm{S}$ receiver functions were migrated into the depth domain to construct depth profiles. The IASP91 global 


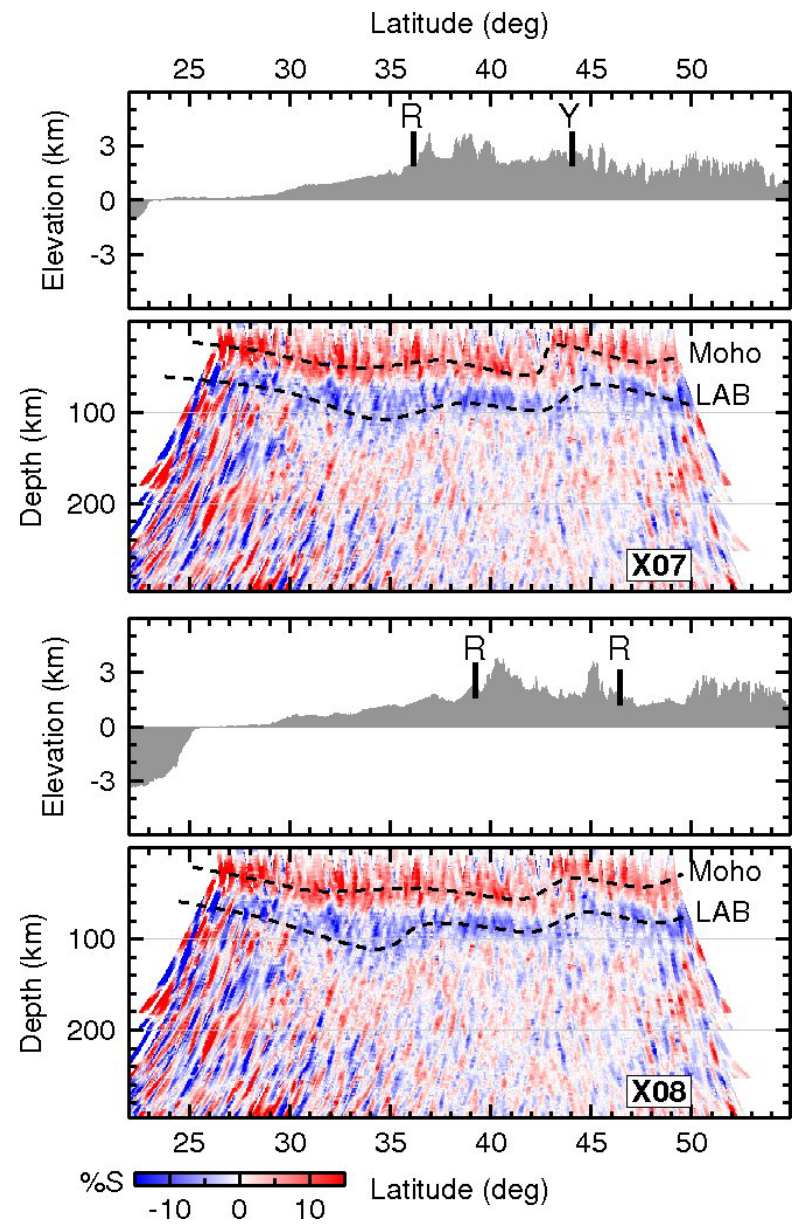

Fig. 16. Migrated S receiver functions along profiles X07 and X08 as in Fig. 3.

reference model was used for the migration. The results are shown along many profiles, each one degree wide. See Fig. 2 for the location of the profiles and Figs. 3-19 for the migrated $\mathrm{S}$ receiver function sections along each profile. The individual "string-like" features in Figs. 3-19 are individual deconvolved seismic records (receiver functions), with time transformed into space along the ray path and color-coded amplitudes. A recent review of the technique can be found in Kind et al. (2012). The difference in the ray coverage and the resulting data quality is obvious between the USArray data in the west and the data from the few permanent stations in the east.

All data show very clearly two significant seismic phases down to the depth of $300 \mathrm{~km}$. Both are of comparable amplitude and frequency content and very similar in appearance in the entire covered area. The deeper one is visible near $100 \mathrm{~km}$ depth and has a negative sign (blue - meaning velocity reduction downward, marked LAB in Figs. 3-19). The shallower one is positive (red - meaning velocity increase downward,

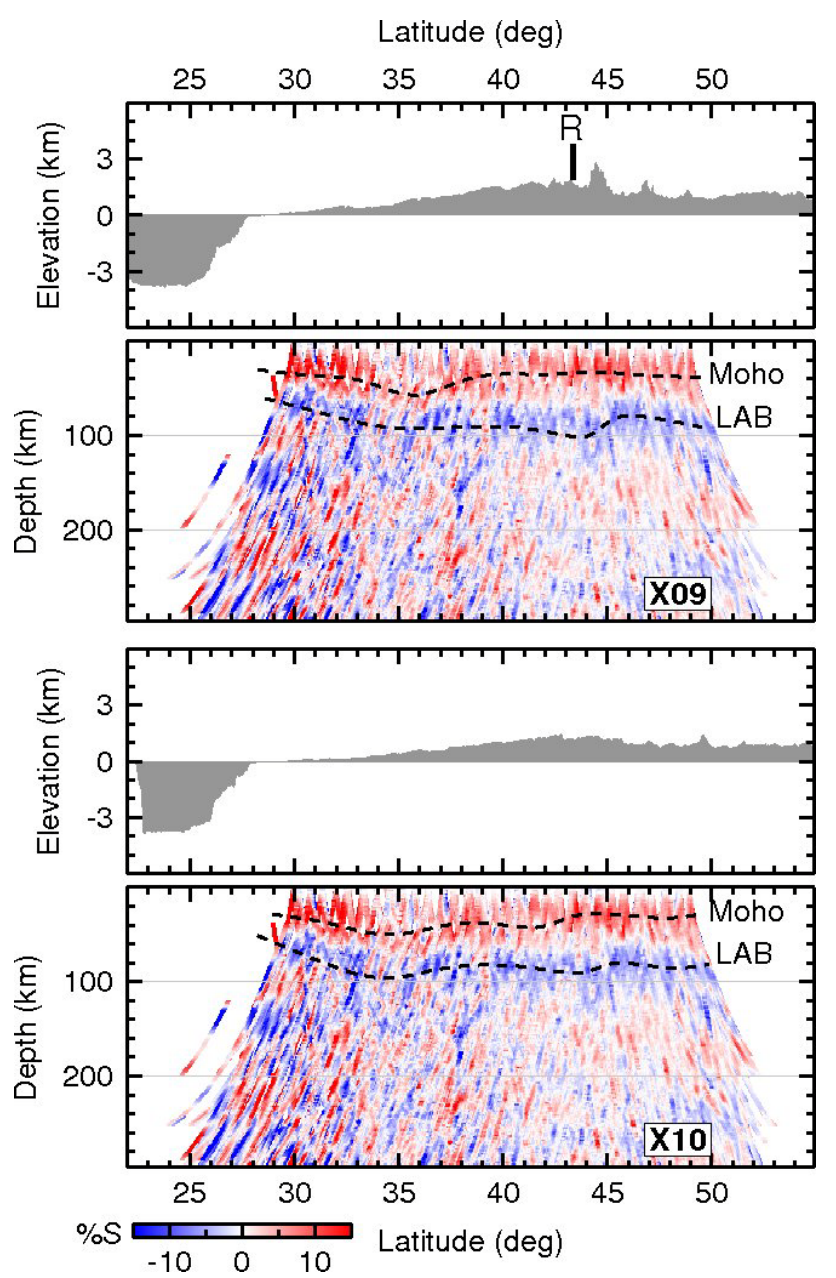

Fig. 17. Migrated S receiver functions along profiles X09 and X10 as in Fig. 3.

marked Moho) and is visible near $40 \mathrm{~km}$ depth. The positive signal is clearly the Moho. The negative signal indicates the general existence of a negative velocity jump underneath the entire study area. We call it the $\mathrm{S}$ receiver function LAB (SRF LAB) following Gutenberg (1926), although this interpretation in the central part of the USA is not in agreement with surface wave results (e.g. Abt et al., 2010).

The Moho signal is not the aim of our present study. P receiver functions are more useful for Moho studies, because they have shorter periods that lead to higher resolution. Besides the Moho and S-RF LAB, no additional phase with comparable amplitude is visible in all $\mathrm{S}$ receiver function data (Figs. 3-19) in the entire region. Especially, no indication of the tomography LAB near $200 \mathrm{~km}$ depth in the cratonic USA is visible. A map of the depth of the S-RF LAB is shown in Fig. 20. The S-RF LAB is at a depth of $70-80 \mathrm{~km}$ in large parts of westernmost North America. East of the Rocky Mountains, its depth is generally between 90 and $110 \mathrm{~km}$. 


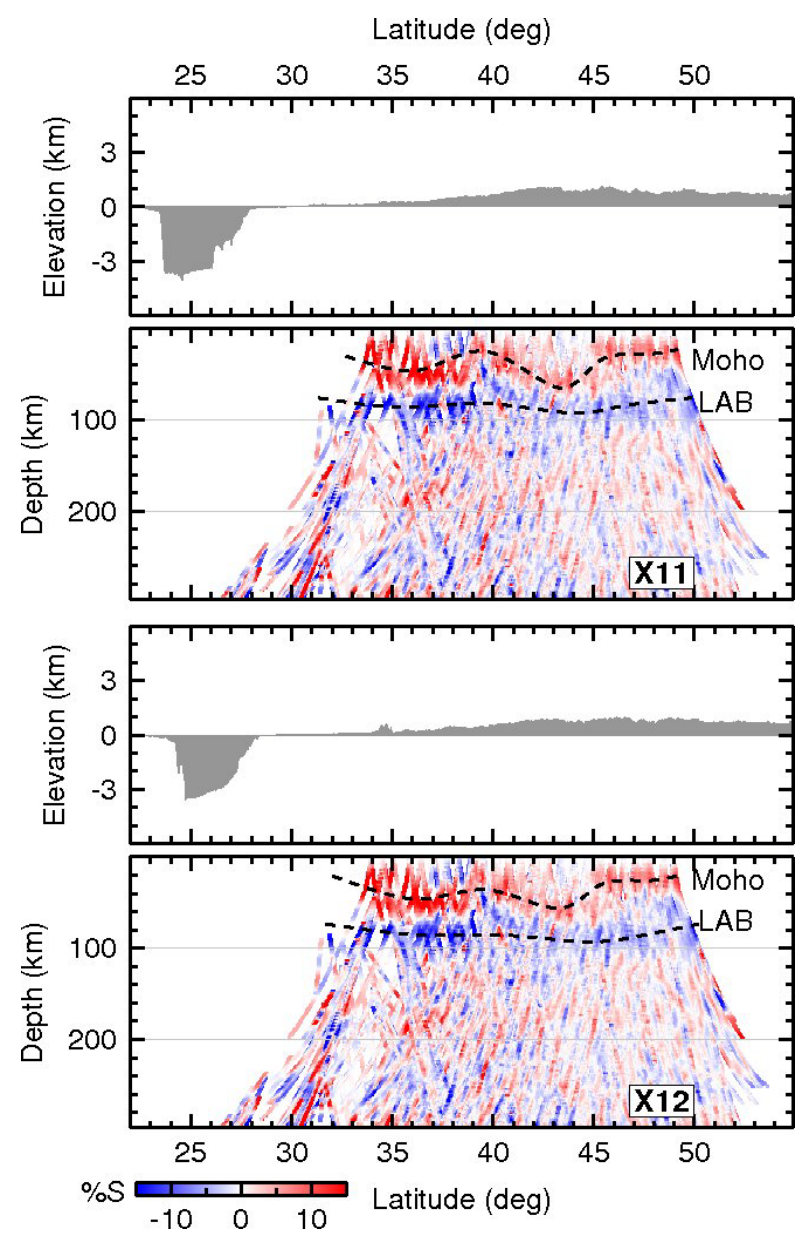

Fig. 18. Migrated S receiver functions along profiles X11 and X12 as in Fig. 3.

Regions with LAB depths down to about $140 \mathrm{~km}$ occur in a stretch from northern Texas, over the Colorado Plateau to the Columbia basalts.

\section{Interpretation, discussion, conclusions}

The stretch of deep LAB structures from the border region of Texas and Oklahoma, over the Colorado Plateau to the Columbia basalts could perhaps be related to fragments of the Farallon slab (e.g. Currie and Beaumont, 2011; Schmandt and Humphreys, 2010). These authors discussed a dissected subducting Farallon slab, with portions basally accreted to the North American craton. Below the Colorado Plateau and the region of the Columbia basalts in the northwest, Pollitz and Snoke (2010) and Obrebski et al. (2011) observed high velocities in tomography data and interpret their observations also by subduction fragments. The deep LAB section in the Texas-Oklahoma border region is located below a Proterozoic mid-continental rift (the Oklahoma aulacogen;
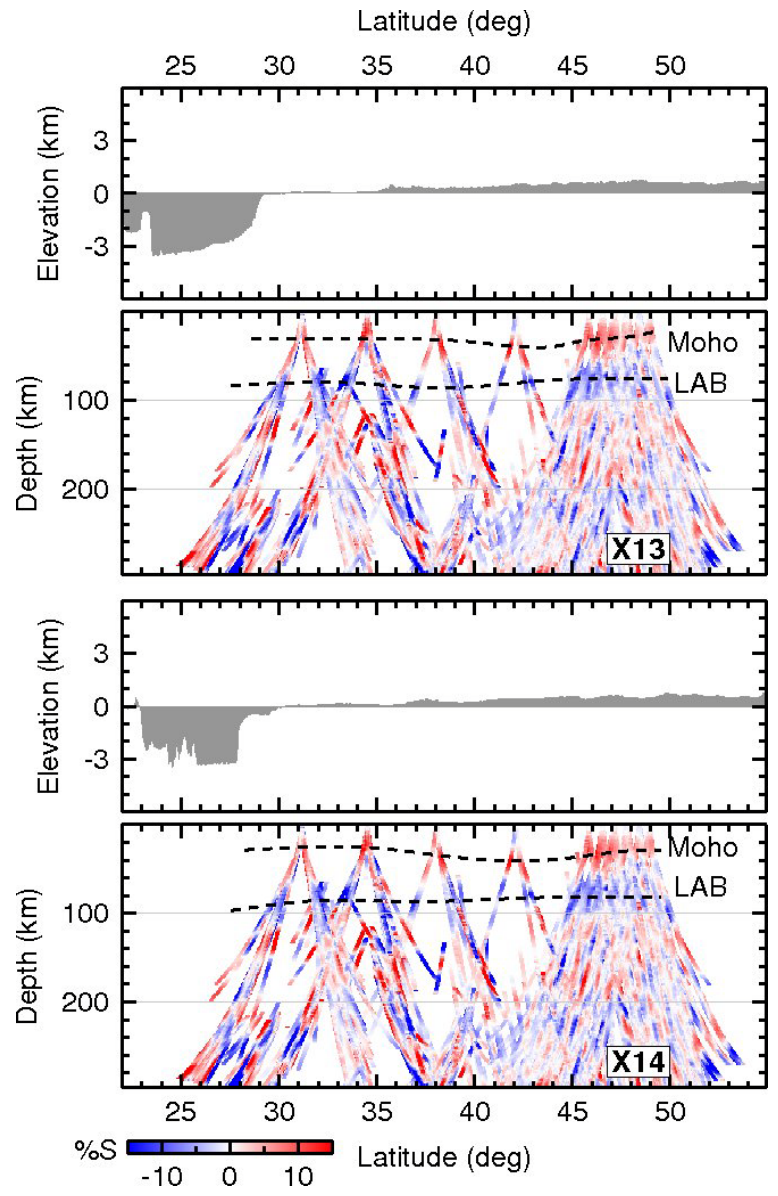

Fig. 19. Migrated S receiver functions along profiles X13 and X14 as in Fig. 3.

e.g. Whitmeyer and Karlstrom, 2007). It is perhaps not to be expected that a rift system is connected with lithospheric thickening. The Cenozoic Rhine Graben, for example, has a lithospheric thickness of $80 \mathrm{~km}$, also from $\mathrm{S}$ receiver functions (Geissler et al., 2010).

Levander et al. (2011) interpreted the high velocity anomaly below the Colorado Plateau, which they also derived from $\mathrm{S}$ receiver functions, as delamination of lower parts of the lithosphere.

Chu et al. (2012) confirmed in the central US the $8^{\circ}$ discontinuity in wide-angle earthquake records. However, they did not discuss in greater detail if their observation is due to a low velocity zone. Kind (1974) found in the mantle lithosphere in western Europe alternating positive and negative gradients in high resolution controlled source data. Chu et al. (2012) also identified the LAB between 165 and $200 \mathrm{~km}$ depth, with $2 \%$ decrease in $\mathrm{P}$ velocity. Such a model would certainly produce only a weak signal in $\mathrm{S}$ receiver functions (see Kind et al., 2012), not comparable with the dominant signal we see in $\mathrm{S}$ receiver functions near $100 \mathrm{~km}$ depth. 


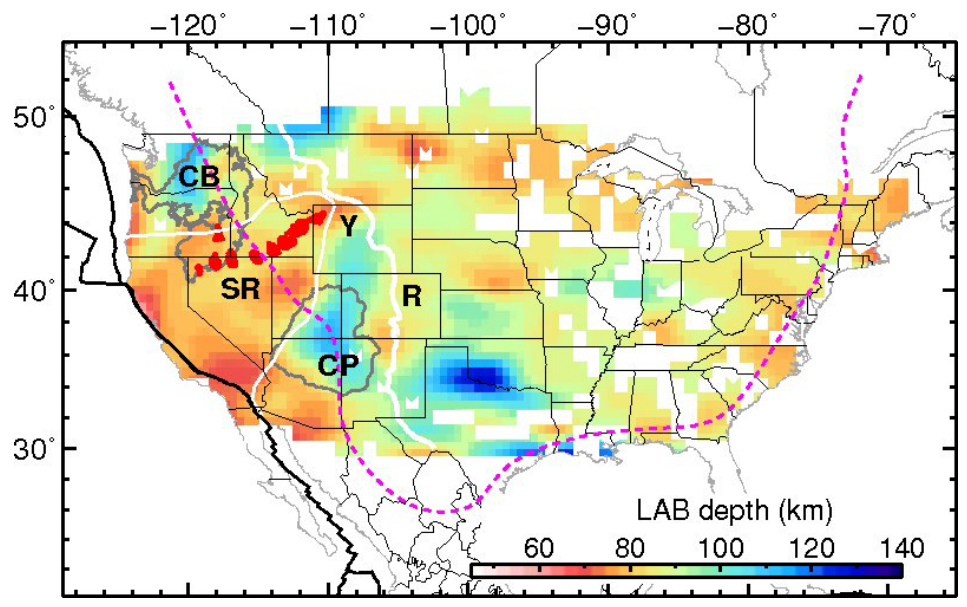

Fig. 20. Map of receiver function LAB. The dashed line marks the region with an approximately $200 \mathrm{~km}$-thick lithosphere obtained from surface wave studies (Yuan and Romanowicz, 2010). Key: see Fig. 1.

Shallow (near $100 \mathrm{~km}$ ) depths of the (possible) LAB beneath most parts of North America have been found by Rychert and Shearer (2009) in P receiver functions. Similar LAB depths have also been found by $\mathrm{Li}$ et al. (2007) on the west coast and by Rychert et al. (2007) on the east coast. Abt et al. (2010) also observed similar depths for a negative discontinuity at a few sparsely distributed stations in the entire USA that are confirmed by our S-RF observations with USArray data. In the central part of the USA, Abt et al. (2010) used the name MLD for the negative discontinuity near $100 \mathrm{~km}$ depth, since the LAB is thought to be deeper. The MLD might be identical with the $8^{\circ}$ discontinuity postulated by Thybo (1997) for the continental mantle globally.

Disagreement between the S-RF LAB and the tomography LAB is not the only case that depth determinations of the LAB with different geophysical methods do not agree (see e.g. the discussion by Eaton et al., 2009). A good comparison of LAB depth determinations with magnetotelluric techniques, receiver function techniques and $\mathrm{P}$ travel time residual techniques in Europe is given by Jones et al. (2010).

The missing confirmation of the deep surface wave LAB (near $200 \mathrm{~km}$ ) by $\mathrm{S}$ receiver functions is interpreted as being caused by a broad negative gradient at this depth, which is supposed to be not visible in $\mathrm{S}$ receiver functions (Romanowicz, 2009). Our data are filtered with an $8 \mathrm{~s}$ low-pass filter. Numerical modeling (Kind et al., 2012) indicates, however, that a gradient, as in Lekic and Romanowicz (2011), should be visible in the $\mathrm{S}$ receiver function data. We conclude therefore that the possible negative gradient at $200 \mathrm{~km}$ should be weaker and spread out over a wider vertical region than previously modeled with long-period surface waves.

Rychert and Shearer (2009) concluded from P receiver functions that the LAB could be about $10 \mathrm{~km}$ sharp. Li et al. (2007) concluded from S receiver functions in the western USA a sharpness of less than $30 \mathrm{~km}$. This argues against a thermal origin of the LAB. A shallow and sharp LAB also beneath continents is, however, explained by hydrous silicate melt caused by excess water in the Mierdel et al. (2007) model. Also, the missing observations of the bottom of the asthenosphere are explained by this model, because it predicts a very smooth velocity increase at the bottom of the asthenosphere. The grain sliding model by Karato (2012) predicts two sharp negative discontinuities in the continental shallow upper mantle. This model would explain our shallow data in North America, but it would produce a second deeper signal, which is not seen in the USArray data. In other cratons (e.g. South Africa) where two negative discontinuities may exist, it could fit better.

Dalton et al. (2011) report about discussions on the global existence of a recently confirmed negative seismic discontinuity at $60-120 \mathrm{~km}$ depth, about its relation to the LAB and how it should be named. Our present results obtained from the USArray data are in agreement with the observations, which have been obtained earlier by e.g. Thybo and Perchuc (1997), Rychert and Shearer (2009) and in reviews of Fischer et al. (2010) or Kind et al. (2012) and in many additional reports on temporary seismic deployments in many parts of the world. It seems that this discontinuity is in its appearance comparable to the Moho, apart from the opposite polarity. Since the Moho is a seismic discovery, it was named by seismologists. The LAB is not a seismic definition. It is therefore not easy to equate any seismic observations with the LAB. Several names for a negative seismic discontinuity in the upper mantle exist already, e.g. Gutenberg discontinuity (also sometimes used for the core-mantle boundary), $8^{\circ}$ discontinuity or now mid-lithospheric discontinuity (MLD). In any case, our data show that the strongest negative discontinuity beneath the entire USA is near $100 \mathrm{~km}$ and not near $200 \mathrm{~km}$. 
Acknowledgements. We wish to thank the Deutsche Forschungsgemeinschaft for their support and the IRIS data center and the USArray project for making their data openly available. PK is thankful to the Director, NGRI (CSIR) for granting him leave.

Edited by: J. Plomerova

\section{References}

Abt, D. L., Fischer, K. M., French, S. W., Ford, H. A., Yuan, H., Romanowicz, B.: North American lithospheric discontinuity structure imaged by Ps and Sp receiver functions, J. Geophys. Res., 115, B09301, doi:10.1029/2009JB006914, 2010.

Barrell, J.: The strength of the Earth's crust, J. Geol., 22, 655-683, 1914.

Chu, R., Schmandt, B., Helmberger, D. V.: Upper mantle P velocity structure beneath the Midwestern United States derived from triplicated waveforms, Geochem. Geophys. Geosyst., 13, Q0AK04, doi:10.1029/2011GC003818, 2012.

Currie, C. A. and Beaumont, C.: Are diamond-bearing Cretaceous kimberlites related to low-angle subduction beneath western North America? Earth Planet. Sci. Lett., 303, 59-70, 2011.

Dalton, C. A., Conrad, C. P., and Trehu, A. M.: What is the lithosphere-asthenosphere boundary? EOS 92, 51, 481, 2011.

Eaton, D. W., Darbyshire, F., Evans, R. L., Grütter, H., Jones, A. G., and Yuan, X.: The elusive lithosphere-asthenosphere boundary (LAB) beneath cratons, Lithos, 109, 1-22, 2009.

Fischer, K. M., Ford, H. A., Abt, D. L., and Rychert, C. A.: The Lithosphere-Asthenosphere Boundary, Ann. Rev. Earth Pl. Sc., 38, 551-575, doi:10.1146/annurev-earth-040809-152438, 2010.

Ford, H. A., Fischer, K. M., Abt, D. L., Rychert, C. A., and ElkinsTanton, L. T.: The lithosphere-asthenosphere boundary and cratonic lithospheric layering beneath Australia from Sp wave imaging, Earth Planet. Sci. Lett., 300, 299-310, 2010.

Geissler, W. H., Sodoudi, F., and Kind, R.: Thickness of the central and eastern European lithosphere as seen by $\mathrm{S}$ receiver functions, Geophys. J. Int., 181, 604-634, doi:10.1111/j.1365246X.2010.04548.x, 2010.

Gutenberg, B.: Untersuchungen zur Frage, bis zu welcher Tiefe die Erde kristallin ist, Zeitschrift für Geophysik, 2, 24-29, 1926.

Jones, A. G., Plomerova, J., Korja, T., Sodoudi, F., and Spakman, W.: Europe from the bottom up: A statistical examination of the central and northern European lithosphere-asthenosphere boundary from comparing seismological and electromagnetic observations, Lithos, 120, 14-29, doi:10.1016/j.lithos.2010.07.013, 2010.

Karato, S.: On the origin of the asthenosphere, Earth Planet. Sci. Lett., 321-322, 95-103, doi:10.1016/j.epsl.2012.01.001, 2012.

Kästle, E. D.: Der Aufbau der Lithosphäre unter Südafrika anhand von P- und S-Receiver-Funktionen, Bachelor Thesis, Universität Potsdam, Institut für Erd- und Umweltwissenschaften, Germany, 2011.

Kind, R.: Long range propagation of seismic energy in the lower lithosphere, J.Geophysics-Z. Geophys., 40, 189-202, 1974.

Kind, R., Yuan, X., and Kumar, P.: Seismic receiver functions and the lithosphere-asthenosphere boundary, Tectonophysics, 536537, 25-43, doi:10.1016/j.tecto.2012.03.005, 2012.
Kumar, P. and Kawakatsu, H.: Imaging the seismic lithosphereasthenosphere boundary of the oceanic plate, Geochem. Geophys. Geosyst., 12, Q01006, doi:10.1029/2010GC003358, 2011.

Kumar, P., Yuan, X., Kind, R., and Ni, J.: Imaging the collision of the Indian and Asian Continental Lithospheres Beneath Tibet, J. Geophys. Res., 111, B06308, doi:10.1029/2005JB003930, 2006.

Kumar, P., Kind, R., Yuan, X., and Mechie, J.: USArray receiver function images of the LAB, Seismol. Res. Lett., 83, 486-491, doi:10.1785/gssrl.83.3.486, 2012.

Lebedev, S., Boonen, J., and Trampert, J.: Seismic structure of Precambrian lithosphere: New constraints from broad-band surfacewave dispersion, Lithos, 109, 96-111, 2009.

Lekic, V. and Romanowicz, B.: Tectonic regionalization without a priori information: A cluster analysis of upper mantle tomography, Earth Planet. Sci. Lett., 308, 151-160, 2011.

Levander, A., Schmandt, B., Miller, M. S., Liu, K., Karlstrom, K. E., Crow, R. S., Lee, C. T. A., and Humphreys, E. D.: Continuing Colorado plateau uplift by delamination-style convective lithospheric downwelling, Nature, 472, 461-466, doi:10.1038/nature10001, 2011.

Li, X., Kind, R., Yuan, X., Wölbern, I., and Hanka, W.: Rejuvenation of the lithosphere by the Hawaiian plume, Nature, 427, 6977, 827-829, 2004.

Li, X., Yuan, X., and Kind, R.: The lithosphere-asthenosphere boundary beneath the western United States, Geophys. J. Int., 170, 700-710, doi:10.1111/j.1365-246X.2007.03428.x, 2007.

Mierdel, K., Keppler, H., Smyth, J. R., and Langenhorst, F.: Water Solubility in Aluminous Orthopyroxene and the Origin of Earth's Asthenosphere, Science, 315, 364-368, 2007.

Miller, M. S. and Eaton, D. W.: Formation of cratonic mantle keels by arc accretion: Evidence from $S$ receiver functions, Geophys. Res. Lett., 37, L18305, doi:10.1029/2010GL044366, 2010.

Obrebski, M., Allen, R. M., Pollitz, F., and Hung, S.-H.: Lithosphere-asthenosphere interaction beneath the western United States from the joint inversion of body-wave traveltimes and surface-wave phase velocities, Geophys. J. Int., 185, 103121, doi:10.1111/j.1365-246X.2011.04990.x, 2011.

Pollitz, F. F. and Snoke, J. A.: Rayleigh-wave phase-velocity maps and three-dimensional shear velocity structure of the western US from local non-plane surface wave tomography, Geophys. J. Int., 180, 1153-1169, doi:10.1111/j.1365-246X.2009.04441.x, 2010.

Priestley, K. and McKenzie, D.: The thermal structure of the lithosphere from shear wave velocities, Earth Planet. Sci. Lett., 244, 285-301, 2006.

Romanowicz, B.: The thickness of tectonic plates, Science, 324, 474-476, doi:10.1126/science.1172879, 2009.

Rychert, C. A. and Shearer, P. M.: A global view of the lithosphere-asthenosphere boundary, Science, 324, 495-498, doi:10.1126/science.1169754, 2009.

Rychert, C. A., Rondenay, S., and Fischer, K. M.: P-to-S and Sto-P imaging of a sharp lithosphere-asthenosphere boundary beneath eastern North America, J. Geophys. Res., 112, B08314, doi:10.1029/2006JB004619, 2007.

Schmandt, B. and Humphreys, E.: Complex subduction and smallscale convection revealed by body-wave tomography of the western United States upper mantle, Earth Planet. Sc. Lett., 297, 435445, 2010.

Thybo, H.: The heterogeneous upper mantle low velocity zone, Tectonophysics, 416, 53-79, 2006. 
Thybo, H., and Perchuc, E.: The seismic $8^{\circ}$ discontinuity and partial melt in the continental mantle, Science, 275, 1626-1629, doi:10.1126/science.275.5306.1626, 1997.

Wegener, A.: Die Entstehung der Kontinente: Petermanns Geographische Mitteilungen, 58, I., 185-195, 253-257, 305-309, 1912.

Whitmeyer, S. J. and Karlstrom, K. E.: Tectonic model for the Proterozoic growth of North America, Geosphere, 3, 220-259, doi:10.1130/GES00055.1, 2007.
Yuan, X., Kind, R., Li, X., and Wang, R.: S receiver functions: Synthetics and data example, Geophys. J. Int., 175, 555-564, 2006.

Yuan, H. Y. and Romanowicz, B.: Lithospheric layering in the North American craton, Nature, 466, 1063-1068, doi:10.1038/nature09332, 2010.

Zhao, W., Kumar, P., Mechie, J., Kind, R., Meissner, R., Wu, Z., Shi, D., Su, H., Xue, G., Karplus, M., and Tilmann, F.: Seismic Evidence for Tibetan Plate overriding Asian Plate, Nat. Geosci., 4, 870-873, doi:10.1038/NGEO1309, 2011. 